\title{
Agroforestry impacts on soil fertility in the Rima'a Valley, Yemen
}

\begin{abstract}
Yemen is one of the world's least developed countries and experiences problems of scarcity of natural agricultural resources as well as soil erosion and degradation. Agroforestry systems (AFS) are being promoted as a more appropriate land use system than monocropping systems (MCS) worldwide. Unfortunately, long-term studies on agroforestry and other land use systems (LUS) do not exist in Yemen. Agroforestry in the Rima'a region has started to deteriorate and many farmers turned to (MCS). This study was conducted in the Rima'a Valley, near Alsharq town, Dhamar, Yemen. The study evaluates the soil nutrients, organic matter (OM), and other soil properties such as $\mathrm{pH}$, bulk density, and porosity under AFS and compares it with soil under MCS. Standard procedures for soil sampling and analyzing were used to collect and analyze 36 composite samples from Site 1 and 36 composite samples from Site 2 from six cropping systems (treatments). The results showed that there were significant variations in relation to LUS. Agroforestry practicesठ mixed trees with coffee (S1), and Cordia africana L. with coffee (S2) have higher nitrogen concentration $(0.17 \mathrm{i} 0.26 \%$ ) as compared to the Ziziphus spina-christi L. with maize (S3) and the monocropping maize (S5), $(<0.16 \%$ in both Sites 1 and 2). Similar results were seen on the effect of the different LUS on the soil P, K, and OM contents at the two sites $(\mathrm{p}<.01)$. While soil $\mathrm{N}, \mathrm{P}$, and soil $\mathrm{K}$ were higher under agroforestry systems S1, and S2 in both sites, it was the lowest in S5 in both sites. It can be concluded that agroforestry has more favorable effects on soil fertility and other soil properties. The government should establish programs and campaigns to disseminate AFS technology and promote the importance of agroforestry in soil conservation.
\end{abstract}

Keyword: Agroforestry; Coffee; Maize; Monocropping; Soil properties 